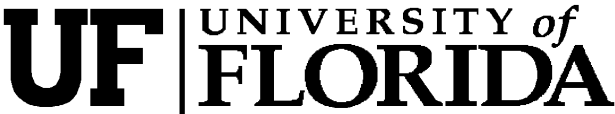 \\ IFAS Extension
}

\section{Exención de Impuestos para Equipos Agrícolas Selectos en Florida ${ }^{1}$}

\section{Edward A. Evans ${ }^{2}$}

Esta publicación es parte de una serie sobre exención de impuestos para productores agrícolas en Florida. Estas publicaciones de EDIS están en la red en

http://edis.ifas.ufl.edu/

topic_series_tax_exemption_for_agricultural_produce rs

\section{Introducción}

El decaimiento de la economía, el incremento de los costos de energía y mano de obra así como los bajos precios de cultivos hortícolas (frutas, hortalizas, nueces y plantas de viveros) han hecho que los productores agrícolas busquen maneras de reducir costos de capital y de operaciones. Una manera en que los agricultores pueden lograr esto es usando todas las exenciones de impuestos a las que son elegibles. Una encuesta tomada recientemente a los productores agrícolas del sur de Florida revela que muchos de ellos no están enterados que son elegibles para las exenciones de impuestos. Una de las exenciones de impuestos a la que son elegibles los productores agrícolas de Florida es la relacionada a los equipos agrícolas motorizados.

\section{Ley de Exención de Impuestos a Equipos Agrícolas Motorizados}

Esta ley pasó durante la sesión legislativa de Florida del 2005 y empezó a regir el primero de julio del mismo año. Esta ley expande provisiones existentes que solo ofrecían exenciones parciales (3\%) por equipo agrícola. La nueva ley exonera todos los impuestos asociados a la compra, venta o alquiler de ciertos equipos motorizados nuevos $O$ usados (Florida Administrative Tax Code 12A-1.087 Sections 1 and 2, Chapter 2005-197).

\section{Equipos Agrícolas incluidos en el Estatuto}

La ley cubre todos los equipos agrícolas motorizados usados exclusivamente en una hacienda o una foresta para realizar actividades tales como arado, plantación, cultivo, cosecha o para la prevención o supresión de incendios en tales cultivos. La ley incluye equipos estacionarios y móviles, esto es, equipos que se mueven con su propio motor y equipos, como sistemas de irrigación, que necesitan una fuente externa de

1. Este es documento EDIS FE789, una publicación del Departamento de Food and Resource Economics, Florida Cooperative Extension Service, Institute of Food and Agricultural Sciences, University of Florida. Publicada en Noviembre 2008. La traducción del inglés al español estuvo a cargo de Carlos Jáuregui. Por favor, visite el sitio de EDIS en la red en http:edis.ifas.ufl.edu. English version (FE715).

2. Edward A. Evans, asistente profesor, departamento de Food and Resource Economics, University of Florida, Tropical Research and Education Center, Homestead, FL, Florida Cooperative Extension Service, Institute of Food and Agricultural Sciences, University of Florida, Gainesville, FL. 
propulsión para funcionar. La ley también aplica a otros equipos usados como fuentes externas de poder, tales como generadores. Ejemplos específicos de equipos motorizados incluyen taladros, cosechadoras, transportadoras, discos, niveladoras, sistemas de alimentación, rastras, empacadoras de heno, motores para irrigación, cortadoras de césped, arados, bombas de agua, vehículos usados en la explotación forestal, y tractores (Florida Department of Revenue 2005). El punto principal es que la exención aplica solo si el equipo va a ser usado exclusivamente con propósitos agrícolas o en actividades relacionadas a la agricultura tales como prevención o supresión de incendios forestales o de otros productos agrícolas.

\section{Trámites para Obtener la Exención de Impuestos}

Para obtener la exención, el comprador o arrendatario del equipo necesita proveer al vendedor (dueño) con un documento firmado que certifique que el equipo comprado será usado solamente "en la hacienda o foresta para arar, plantar, cultivar, cosechar productos agrícolas o para la prevención y supresión de incendios en dichos cultivos o productos" (Florida Department of Revenue 2005). El Apendice A al final de esta publicación provee una muestra que fue preparada por el Florida State Department of Revenue (Departamento de Rentas del Estado de Florida).

\section{Conclusión}

Productores agrícolas, particularmente aquellos que no producen granos, están sintiendo los efectos de una economía lenta y del aumento en el costo de los insumos. La ley de exención de impuestos a equipos agrícolas del 2005, que expandió la exención de parcial a total así como la variedad de equipos exonerados, tiene como objetivo proveer a los productores agrícolas con más incentivos, dados los grandes riesgos envueltos en la producción agrícola. Los productores agrícolas que no están enterados de estas provisiones pagan impuestos innecesarios que de otra manera contribuirían a las ganancias del negocio agrícola. Por ejemplo, por un equipo que cuesta $\$ 10,000$ se pagarían $\$ 700$ en exceso y por un equipo de $\$ 50,000$ se pagarían
$\$ 3,500$ en exceso. Por lo tanto, el propósito de este artículo es el de difundir el conocimiento de esta ley entre los productores agrícolas para que usen las exenciones a las que tienen derecho.

\section{Recursos}

Para mayor información ver en la red el sitio del State of Florida Department of Revenue, http://www.myflorida.com/dor, o llame al Florida

Taxpayer Services al teléfono 1 (800) 367-8331.

\section{Referencias}

Florida Department of Revenue. 2005. HB 0643: Expansion of the exemption for certain farm equipment. Tax Information Publication No. 05A01-03, Florida Department of Revenue, Tallahassee, FL (June 15). http://dor.myflorida.com/dor/tips/tip05a01-03.html 


\section{Apendice A.}

\section{CERTIFICADO DE EXENCION CIERTOS EQUIPOS AGRICOLAS MOTORIZADOS}

Esto es para certificar que el equipo agricola motorizado, identificado abajo, comprado el (fecha) de (Nombre del negocio del vendedor) es comprado, dado en licencia o alquilado con los siguientes propositos:

( ) Equipo agricola motorizado para el uso exclusivo en la produccion agricola de cultivos o productos, producidos de manera como los producen las industria agricolas incluidas en $\S 570.02(1)$, F.S.

( ) Equipo agricola motorizado para el uso exclusivo en la prevencion y supresion de incendios en cultivos o productos, producidos de manera como los producen las industria agricolas incluidas en $\S 570.02(1)$, F.S.

EQUIPO AGRICOLA MOTORIZADO:

Entiendo que si uso el equipo con otro proposito, diferente al que he especificado, pagare impuestos sobre el precio de venta o alquiler del equipo directamente al Departamento de Rentas. Entiendo que si uso fradulentamente este certificado para evadir los impuestos sere responsable por el pago de impuestos ademas de una multa del $200 \%$ de dicho impuesto y podria estar sujeto a una conviccion de felonia del tercer grado.

La exencion especificada por el comprador puede ser verificada llamando al 1 (800) 352-3671.

Nombre del comprador:

Direccion del comprador:

Nombre y titulo del representante autorizado del comprador:

Por:

(Firma del comprador o representante autorizado)

Titulo:

(Titulo — solo si ha sido comprado por el representante autorizado de una empresa)

Fecha: 